\title{
Suppression of WWP1 Gene Via RNAi Induced the Reduction of Proliferation Rate of $\mathrm{C}_{2} \mathrm{C}_{12}$ Myoblasts
}

\author{
Hirokazu Matsumoto, Michihiro Takahama, Ryohsuke Kajiyama, \\ Shinji Sasazaki, Kenji Oyama and Hideyuki Mannen \\ Laboratory of Animal Breeding and Genetics, Graduate School of Agricultural Science, \\ Kobe University, Kobe 657-8501, Japan
}

\begin{abstract}
The WW domain containing E3 ubiquitin protein ligase 1 (WWP1), which plays an important role in ubiquitinproteasome pathway to degrade unneeded or damaged proteins, was recently identified as the responsible for chicken muscular dystrophy. Despite intensive studies on oncogenic characters, the role of WWP1 to muscular diseases has not yet been fully understood. Previously, we transfected either of wild and mutated types of $W W P 1$ gene into $\mathrm{C}_{2} \mathrm{C}_{12}$ mouse myoblasts to monitor the expression pattern of muscle-differentiation markers, so that excessive $W W P 1$ expression enhanced the expression of the myosin heavy chain $(M y H C)$ Ia gene but lowered the expression of the $M y H C I I b$ gene, while mutated $W W P$ 1 gene transfected into myoblasts was distinct from these cases in that the $M y H C$ gene or genes expression inhibited the normal myoblast differentiation. However, the mechanism for the mutation to inhibit muscle differentiation remains elucidated. The current study attempted to suppress the $W W P 1$ expression by RNAi technique and to observe its effect on $\mathrm{C}_{2} \mathrm{C}_{12}$ cells. The effect of WWP1 suppression was clearly different from that of the R441Q missense mutation in the WWP1 gene. The $W W P 1$ suppression reduced the proliferation rate of $\mathrm{C}_{2} \mathrm{C}_{12}$ myoblasts, while clear difference was not observed in the proliferation rate by the transfection of the mutated WWP1 gene into the cells. Our RT-PCR analysis indicated that the reduction of the WWP1 expression is the specific effect mediated by RNAi and that the reduction of proliferation rate observed in this study is largely attributed to the suppression of the WWP1 expression. These data indicated that the mutation responsible for chicken muscular dystrophy does not eliminate the enzymatic activity and provides some new function for the gene.
\end{abstract}

Key words: $\mathrm{C}_{2} \mathrm{C}_{12}$, chicken, muscular dystrophy, RNAi, WWP1

J. Poult. Sci., 47: 288-293, 2010

\section{Introduction}

Ubiquitination, addition of ubiquitin (Ub) chains to a target protein, is one of the most common forms of posttranslational modification, and it controls various important aspects of cell functions including protein degradation, DNA damage tolerance and signal transduction (Passmore and Barford, 2004; Pickart and Fushman, 2004). In ubiquitin-proteasome pathway (UPP), at least three types of enzymes are required: E1 Ub-activating enzyme, E2 Ub-conjugating enzyme and E3 Ub ligase (Hershko et al., 1983). Comparative genome analysis reveals the existence of few genes encoding E1, tens of E2 encoding genes and hundreds of E3 encoding genes (Semple et al., 2003).

The WW domain containing E3 ubiquitin protein ligase

Received: May 11, 2010, Accepted: June 25, 2010

Released Online Advance Publication: July 25, 2010

Correspondence: H. Mannen, Graduate School of Agricultural Science,

Kobe University, Kobe 657-8501, Japan.

(E-mail: mannen@kobe-u.ac.jp)
1 (WWP1) is classified into a HECT (homologous to the E6-AP carboxyl terminus)-type E3 which recognizes and catalyzes $\mathrm{Ub}$ conjugation to specific protein substrates (Liu, 2004). WWP1 possesses one C2 domain, multiple WW domains and one HECT domain (Pirozzi et al., 1997; Flasza et al., 2002). The $\mathrm{C} 2$ domain binds to the cellular membranes in a $\mathrm{Ca}^{2+}$-dependent manner (Plant et al., 1997) and mediates interactions with other proteins (Plant et al., 2000; von Poser et al., 2000; Augustine, 2001). The WW domain has two conserved tryptophan residues and binds proline-rich region (Sudol et al., 1985). The HECT domain, similar to E2s structurally, has a cysteine residue as an active center that transfers the activated Ub from $\mathrm{E}$ 2 onto first itself, and then onto its substrates (Jackson et al., 2000).

The relationship between WWP1 and breast and prostate cancer was intensively studied and some proteins involving cancer development have been elucidated (Chen and Metasic, 2007; Bernassola et al., 2008). Knockdown of $W W P 1$ induces growth arrest and apoptosis in breast epithelial cancer cell lines, substantiating the concept that 
WWP1 promotes cell proliferation and survival of tumor cells (Chen et al., 2007). Recently, we identified the WWP1 gene as the responsible gene for the chicken muscular dystrophy, and the R441Q missense mutation in the WWP1 gene was found to be the cause of muscular dystrophic phenotype (Matsumoto et al., 2007, 2008). The WWP1 gene is expressed strongly in skeletal muscles (Flasza et al., 2002; Komuro et al., 2004; Matsumoto et al., 2009), but the role which WWP1 plays in skeletal muscles is still unclear.

Previously we transfected the wild and mutated types of the $W W P 1$ gene into $\mathrm{C}_{2} \mathrm{C}_{12}$ cells which were myoblasts derived from the mice skeletal muscle and analyzed its effect on muscle differentiation (Matsumoto et al., 2010). The $\mathrm{C}_{2} \mathrm{C}_{12}$ cells were used instead of chicken myoblasts since they were easily obtained and chicken cultured cells were not available. Excessive $W W P 1$ expression enhanced the expression of the myosin heavy chain $(\mathrm{MyHC}) \mathrm{Ia}$ gene but lowered the expression of the $M y H C I I b$ gene. On the other hand, mutated WWP1 gene transfected into myoblasts was distinct from these cases in that the $M y H C$ gene or genes expression inhibited the normal myoblast differentiation. The data suggested that WWP1 promotes myoblast differentiation from embryonic into fast twitch phase while a mutation in WWP1 results to retain slow and fast twitch isoforms characteristic of dystrophic fast twitch muscles. But the mechanism for the mutation to inhibit muscle differentiation still remains elucidated. In the current study, we applied RNAi technique to suppress the $W W P 1$ expression in $\mathrm{C}_{2} \mathrm{C}_{12}$ cells for the comparison of the effect induced by WWP1's suppression with that by the mutation in WWP1 observed in the previous study (Matsumoto et al., 2010). The information obtained by this study will help understand the mechanism of chicken muscular dystrophy.

\section{Materials and Methods}

\section{shRNA Design and Plasmid Construction}

The RNAi vectors were constructed with BLOCK-iT U6 RNAi Entry Vector Kit (Invitrogen, CA, USA). The cDNA sequence of WWP1 was obtained from GenBank (accession number NM_177327). The siRNA target design tool from Invitrogen (RNAi Designer) was used to design WWP1-shRNA sequences. WWP1-shRNA sequences were designed and synthesized as follows (sense target sequence underlined): WWP1, sense: 5'-CACCGCTGATAATACTTCAACCATGCGAACATGGTTGAAGTATTATCAGC-3' and antisense: $3^{\prime}$-CGACTATTATGAAGTTGGTACGCTTGTACCAACTTCATAATAGTCGAAAA-5'. The oligonucleotides were annealed and inserted into $\mathrm{pENTR} \mathrm{TM}^{\mathrm{TM}} / \mathrm{U} 6$ using T4 DNA Ligase. Inserted sequences were verified by DNA sequencing.

In order to exclude the possibility of off-target effects, three other WWP1-shRNA sequences were prepared and their effects were analyzed: WWP1-O1, sense: 5'-CACCGAGTTGATGATCGTGGAAGCGAACTTCCACGATCATCAACTC-3' and antisense: $3^{\prime}$-CTCAACTACTA-
GCACCTTCGCTTGAAGGTGCTAGTAGTTGAGAAAA-5', WWP1-O2, sense: 5'-CACCGACACGGTTAATGGAGAATCACGAATGATTCTCCATTAACCGTGTC-3' and antisense: $3^{\prime}$-CTGTGCCAATTACCTCTTAGTGCTTACTAAGAGGTAATTGGCACAGAAAA-5' and WWP1-O3, sense: 5'-CACCGCATCCTCAGAACACAGTGAACGAATTCACTGTGTTCTGAGGATGC-3' and antisense: 5'-CGTAGGAGTCTTGTGTCACTTGCTTAAGTGACACAAGACTCCTACGAAAA-3'.

\section{Cell Culture and Transfection Conditions}

The $\mathrm{C} 3 \mathrm{H}$ murine skeletal muscle cell line $\mathrm{C}_{2} \mathrm{C}_{12}$ (CRL1722) was commercially obtained from the American Type Culture Collection (ATCC), VA, USA. Cells were cultured in the growth medium: Dulbecco's modified Eagle's medium (DMEM) (Nissui, Tokyo, Japan) containing $0.2 \%$ sodium hydrogen carbonate (Nakalaitesque, Kyoto, Japan), 0.008\% kanamycin (Wako, Osaka, Japan) and L-glutamine $(10 \mu \mathrm{g} / \mathrm{ml})$ (Nissui), supplemented with $10 \%$ fetal bovine serum (FBS) (Gibco, NY, USA). The cells were incubated at $37^{\circ} \mathrm{C}$ in humidified $95 \%$ air and $5 \% \mathrm{CO}_{2}$ atmosphere.

$\mathrm{C}_{2} \mathrm{C}_{12}$ cells were cultured overnight to $80 \%$ confluence prior to transfection. Transfection was performed using Opti-MEM $^{\circledR}$ I Reduced Serum Medium (Gibco), Plus reagent (Invitrogen) and Lipofectamine ${ }^{\mathrm{TM}}$ LTX (Invitrogen). The ratio of the plasmids and the transfection reagent was $1 \mathrm{mg}$ : $2 \mathrm{ml}$. Following the protocol's specifications, cells were transfected with different vectors: pENTR $^{\mathrm{TM}} / \mathrm{U} 6-\mathrm{WWP1}$-shRNA, pENTR ${ }^{\mathrm{TM}} / \mathrm{U} 6-\mathrm{WWP1-O}-$ 1-3-shRNA and pcDNA $^{\mathrm{TM}} 3.1$ / His/lacZ control vector of $\beta$-Gal Staining Kit (Invitrogen). Transfection efficiency of the RNAi was $>60 \%$, as determined by $\beta$-Gal Staining Kit (Invitrogen).

\section{Semi-Quantitative RT-PCR Analysis}

Total RNA was isolated from cells using Sepasol RNAI (Nakalaitesque). The cDNA was generated by reverse transcription using oligo (dT) primer and SuperScript III Reverse Transcriptase (Invitrogen). The expressions of WWP1 and its structurally similar genes (WWP2, Itchy1, Nedd4-2, Nedd4-1, Smurf2, Smurf1) were analyzed by the semi-quantitative RT-PCR method using $G A P D H$ as an internal standard. Gene similarity was assessed by Protein BLAST (http://www.ncbi.nlm.nih.gov/BLAST/) and genes with $>400$ bits (score) were regarded as the similar genes. The PCR was done for 35,37 and 39 cycles at $94^{\circ} \mathrm{C}$ for $30 \mathrm{sec}, 55^{\circ} \mathrm{C}$ for $30 \mathrm{sec}, 72^{\circ} \mathrm{C}$ for $30 \mathrm{sec}$ using TaKaRa Ex $\operatorname{Taq}^{\mathrm{TM}}$ Hot Start Version (Takara, Tokyo, Japan) as the DNA polymerase. All of the primer pairs in this procedure, designed by OLIGO 4.0 program (National Biosciences, MN, USA), are shown in Table 1. PCR products were subjected in electrophoresis in an ethidium bromide-added 1\% agarose gel. The band density was calculated with Scion Image (Scion Corporation, MD, USA). Expression levels for each gene were calculated as relative expression levels toward GAPDH mRNA expression using the band of 37 cycles. For each gene, three 
Table 1. Primers used for semi-quantitative RT-PCR

\begin{tabular}{|c|c|c|c|c|}
\hline Name & GenBank accession \# & Sequence $\left(5^{\prime} \rightarrow 3^{\prime}\right)^{1}$ & Scores (bits) $)^{2}$ & Identities $(\%)^{3}$ \\
\hline$W W P 1$ & NM_177327 & $\begin{array}{l}\text { CCTTGGAGTTCCGAGTTTGGA } \\
\text { AGTTCCCCAGTTTGCACTATTC }\end{array}$ & 1917 & 100 \\
\hline$W W P 2$ & NM_025830 & $\begin{array}{l}\text { ATATGCTGGGAAGAACAATTACT } \\
\text { AATGGAGTTGTAAAACTCAGGGT }\end{array}$ & 1094 & 60 \\
\hline Itchy1 & NM_008395 & $\begin{array}{l}\text { AAACAACGCCTTAACCCTAAGAA } \\
\text { GACTCCACACACGAAAACATAAT }\end{array}$ & 1088 & 60 \\
\hline Nedd4-2 & NM_031881 & $\begin{array}{l}\text { ACCATTTGTCCTATTTCACCTTC } \\
\text { TTACCATTATTTCTGACCCGTTG }\end{array}$ & 517 & 45 \\
\hline Nedd4-1 & NM_010890 & $\begin{array}{l}\text { AGTTGTGAGAGTGAAGGTTATAG } \\
\text { AGGAAATCATCTCTTGTCAAACG }\end{array}$ & 489 & 45 \\
\hline Smurf2 & NM_025481 & $\begin{array}{l}\text { TGACCATAACAACAGAACAACAC } \\
\text { TTCCTCAAAAATCTCTTCCCTAG }\end{array}$ & 483 & 44 \\
\hline Smurf1 & NM_001038627 & $\begin{array}{l}\text { AGATCACAATAATAGGACAACCC } \\
\text { ACAAAGTGGAAGTATGACAGATG }\end{array}$ & 467 & 63 \\
\hline$G A P D H$ & NM_008084 & $\begin{array}{l}\text { AGGTCGGTGTGAACGGATTTG } \\
\text { TGTAGACCATGTAGTTGAGGTCA }\end{array}$ & - & - \\
\hline
\end{tabular}

${ }^{1}$ Each column's upper primers are forward primers and lower ones reverse primers.

${ }^{2}$ Genes with $>400$ bits in BLAST were regarded as the similar genes.

${ }^{3}$ Identities of amino acid sequence are shown.

individual samples were prepared.

\section{Proliferation Rate of the Cell}

$\mathrm{C}_{2} \mathrm{C}_{12}$ cells were observed by optical microscope and the number of cells was counted manually immediately after and 24 hours after transfection. Five observation sites were randomly selected for one condition. Proliferation rates were calculated as relative levels toward the cell numbers of just after transfection. For each calculation, three individual samples were prepared.

\section{Statistical Analysis}

Values in this paper represent means \pm S.D. Differences between two groups were examined for statistical significance using Student's $t$ test. A $P$ value less than 0.05 denoted the presence of a statistically significant difference.

\section{Results and Discussion}

We previously suggested the mutation in the WWP1 gene disrupts the myoblasts' differentiating process to result in muscular dystrophic phenotype (Matsumoto et al., 2010). However, the mechanism for the mutation to inhibit muscle differentiation remains elucidated. The current study attempted to suppress the $W W P 1$ expression by RNAi technique and to observe its effect on $\mathrm{C}_{2} \mathrm{C}_{12}$ mouse myoblasts. For this purpose, $\mathrm{pENTR}^{\mathrm{TM}} / \mathrm{U} 6-\mathrm{WWP}$ 1-shRNA vector (shWWP1) was constructed and its effect on $\mathrm{C}_{2} \mathrm{C}_{12}$ cells was analyzed and compared with pcDNA $^{\mathrm{TM}}$ 3.1/His/lacZ control vector (shLacZ)-transfected and untransfected cells. The capacity of shWWP1 vector was assessed by semi-quantitative RT-PCR using GAPDH gene as an internal control (Fig. 1). Though the transfection efficiency was not high enough $(>60 \%$, not shown), the WWP1 expression of shWWP1-transfected cells was successfully reduced to $54 \pm 0 \%$ compared with that of shLacZ-transfected control cells.

Unintended effects on gene expression mediated by RNAi, off-target effects, should be concerned when applying RNAi technique. Off-target effects are divided into two types: specific and nonspecific off-target effects. Specific off-target effects are mediated by partial sequence complementarity of the RNAi construct to mRNAs other than the intended target (Rao et al., 2009). In order to confirm the specificity in RNAi mediated gene silencing, not only the WWP1 expression but the expressions of its structurally similar genes were analyzed. The $W W P 2$, Itchy1, Nedd4-2, Nedd4-1, Smurf2 and Smurf1 were selected as the genes similar to WWP1 according to the BLAST score (Table 1), although these genes did not have homologue sequence with the RNAi sequence. Their expressions in shWWP1-transfected cells were $92 \pm 7 \%$

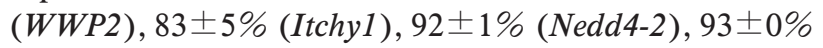
(Nedd4-1), 90 $\pm 2 \%$ (Smurf2) and $92 \pm 3 \%$ (Smurf1) (Fig. 1). Though the expressions of all genes examined were reduced, their downward trends were not as sharp as that of $W W P 1$ and the differences of WWP1 expression with the expressions of the other genes were significant, suggesting the reduction of the WWP1 expression in shWWP1-transfected cells is the specific effect mediated by the RNAi.

Twenty-four hours after transfection, the proliferation rate of shWWP1-transfected cells was significantly reduced to $89 \pm 35 \%$, though that of shLacZ-transfected cells was $161 \pm 21 \%$ and untransfected cells $263 \pm 53 \%$ (Fig. 2, 3). The $W W P 1$ suppression reduced the proliferation rate of $\mathrm{C}_{2} \mathrm{C}_{12}$ myoblasts, while clear difference was not observed in the proliferation rate by the transfection of the mutated WWP1 gene into the cells (Matsumoto et al., 2010). The effect of $W W P 1$ suppression was clearly dif- 


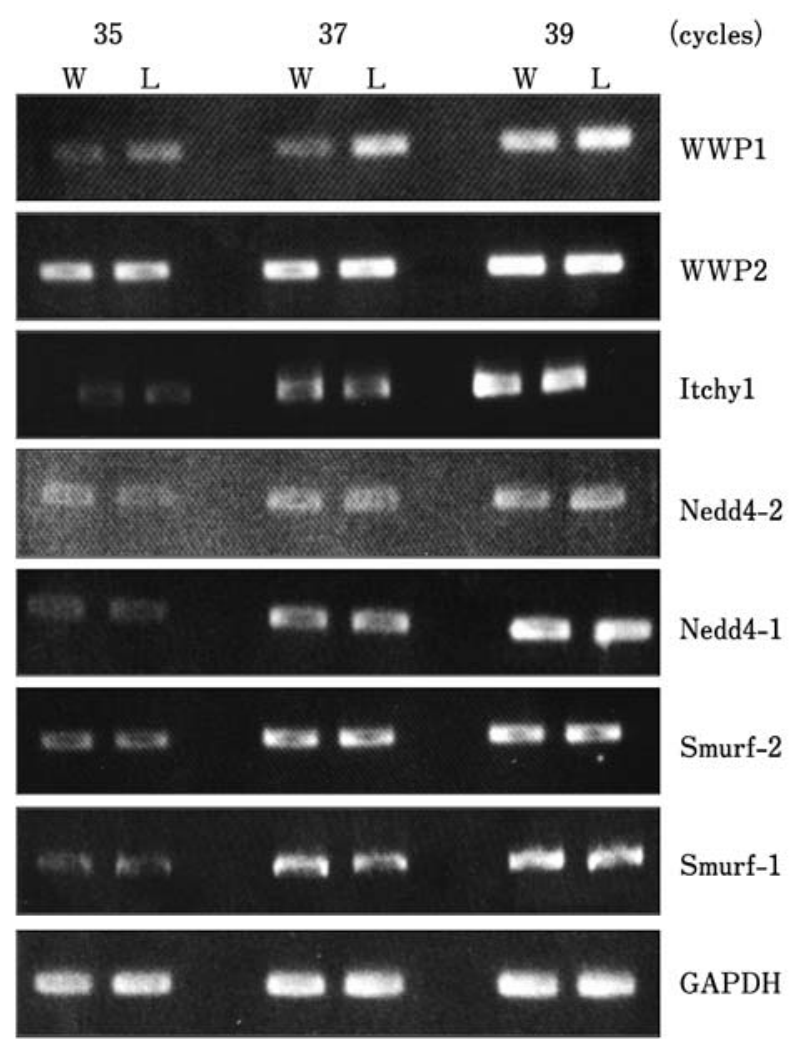

Fig. 1. Confirmation of the specificity in RNAi mediated gene silencing. Expression of $W W P 1$ and its structurally similar genes, WWP2, Itchy1, Nedd4-2, Nedd4-1, Smurf-2 and Smurf-1, in shWWP1-transfected (W) and shLacZtransfected cells (L) was analyzed by the semi-quantitative RT-PCR method using GAPDH as an internal standard. The PCR was performed for 35, 37 and 39 cycles. Though the WWP1 expression in $\mathrm{W}$ was reduced to $54 \pm$ $0 \%$ compared with $\mathrm{L}$, expressions of the others were not significantly altered. Three individual samples were prepared for each gene and the representative images were shown.

ferent from that of the R441Q missense mutation in the $W W P 1$ gene, indicating that the mutation responsible for chicken muscular dystrophy does not eliminate the enzymatic activity and provides some new function for the gene.

In order to exclude the possibility of the nonspecific off-target effects, we designed three other WWP1-shRNA sequences (shWWP1-O1-3) and observed their effects on $\mathrm{C}_{2} \mathrm{C}_{12}$ cells (Fig. 3). Nonspecific off-target effects include a wide variety of immune and toxicity related effects that are intrinsic to the RNAi construct itself or its delivery vehicle (Rao et al., 2009). All cells with shWWP1-O1-3 vectors showed similar downward tendencies to shWWP1transfected cells in terms of proliferation rate (shWWP1O1: $101 \pm 22 \%$, shWWP1-O2: $83 \pm 16 \%$ and shWWP1O3: $110 \pm 22 \%)$. Though all transfected cells exhibited downward trends compared with untransfected cells, sig- nificant difference did exist only between shLacZ-transfected cells and shWWP1s-transfected cells. The reduction of proliferation rate observed in this study might be largely attributed to the suppression of the WWP1 expression.

The suppression of the WWP1 expression might induce apoptosis and/or cell-cycle arrest. One of known proteins interacting with WWP1 is Notch (Flasza et al., 2006), which regulates various proteins involved in apoptosis and cell-cycle such as NF- $\kappa \mathrm{B}$, Akt, Cyclin D1 and CDK2 (Oswald et al., 1998; Katso et al., 2001; Ronchini et al., 2001; Palomero et al., 2008). The WWP1 suppression might lead the aberration of these proteins to reduce the proliferation rate of $\mathrm{C}_{2} \mathrm{C}_{12}$ cells. In addition, the ablation of Notch in a skeletal muscle results in increased formation of fast twitch fibers and altered fiber type distribution at the expense of slow twitch fibers (Kitamura et al., 2007). In chicken muscular dystrophy, the switching of the adult phenotype in fast muscle is inhibited (Bandman, 1985; Bandman and Bennett, 1988; Kaprielian et al., 1991; Tidyman et al., 1997), suggesting the WWP1-Notch interaction plays an important role for muscle to develop normally. Therefore, WWP1 suppressed chickens via RNAi could exhibit muscular dystrophic phenotype, since accumulation of WWP1's substrates is expected to result in the phenotype. However, the chickens might not show the phenotype because of the functional redundancy among members of the NEDD4 family including WWP1 (Chen and Metasic, 2007).

In the current study, we suppressed the WWP1 expression and observed its effect on $\mathrm{C}_{2} \mathrm{C}_{12}$ myoblasts. The reduction of proliferation rate was observed due to the WWP1 suppression, which was an effect apart from the mutation in WWP1. Elucidating the mechanism of the reducing proliferation rate via the $W W P 1$ suppression and the characteristic of the mutation responsible for chicken muscular dystrophy will contribute to the understanding of the role that $W W P 1$ gene plays in skeletal muscle.

\section{Acknowledgments}

This work was supported in part by Grant-in-Aid for Scientific Research (C), no. 19580338, and the Global COE Program "Global Center for Education and Research in Integrative Membrane Biology" (A-8) from the Ministry of Education, Science, Sports and Research on Nervous and Mental Disorders (16B-2, 19A-7) from the Japanese Ministry of Health, Labor and Welfare. 
$0 \mathrm{H}$
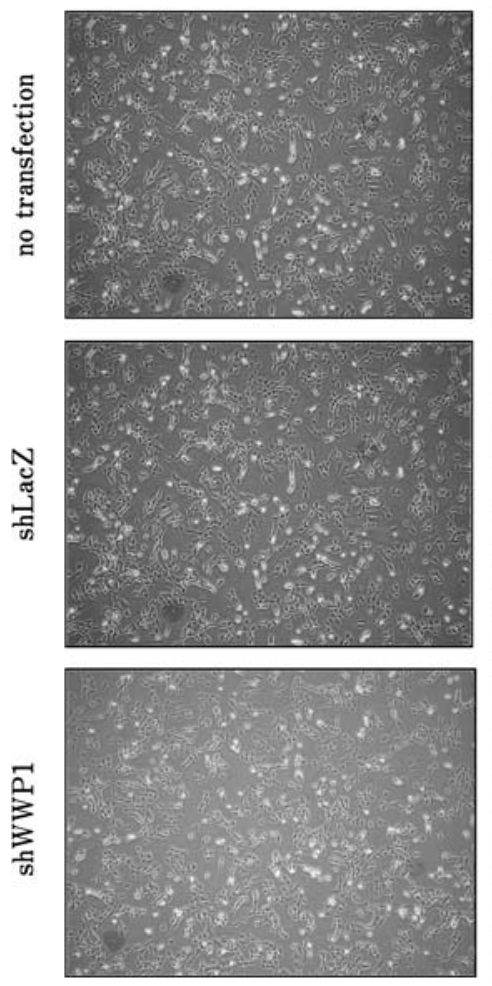

$24 \mathrm{H}$
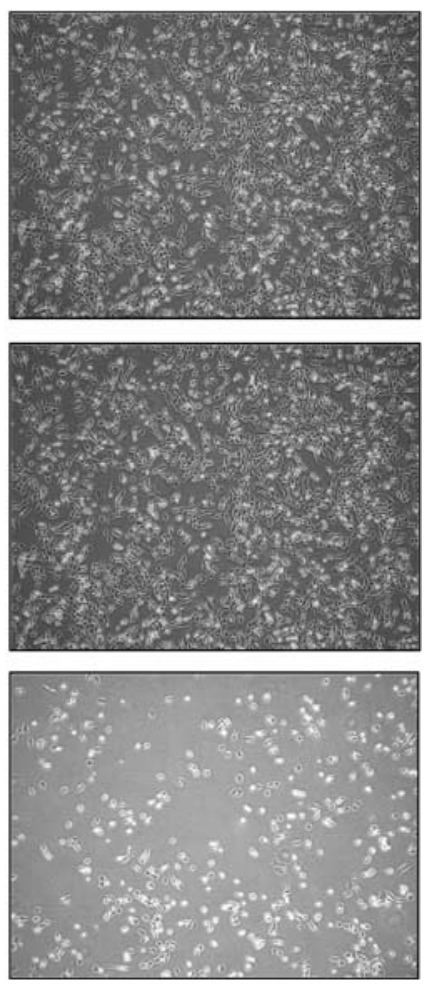

Fig. 2. Reduction of proliferation rate in $W W P 1$ suppressed $\mathbf{C}_{2} \mathbf{C}_{12}$ cells. Twenty-four hours after transfection $(24 \mathrm{H}), \mathrm{C}_{2} \mathrm{C}_{12}$ cells were observed by optical microscope and the number of cells was counted manually. The proliferation rate of shWWP1-transfected cells was significantly reduced to $89 \pm 35 \%$, though that of shLacZ-transfected cells was $161 \pm 21 \%$ and untransfected cells $263 \pm 53 \%$. Proliferation rates were calculated as relative levels toward the cell numbers of immediately after transfection $(0 \mathrm{H})$. Three individual samples were prepared for each calculation and the representative images were shown.
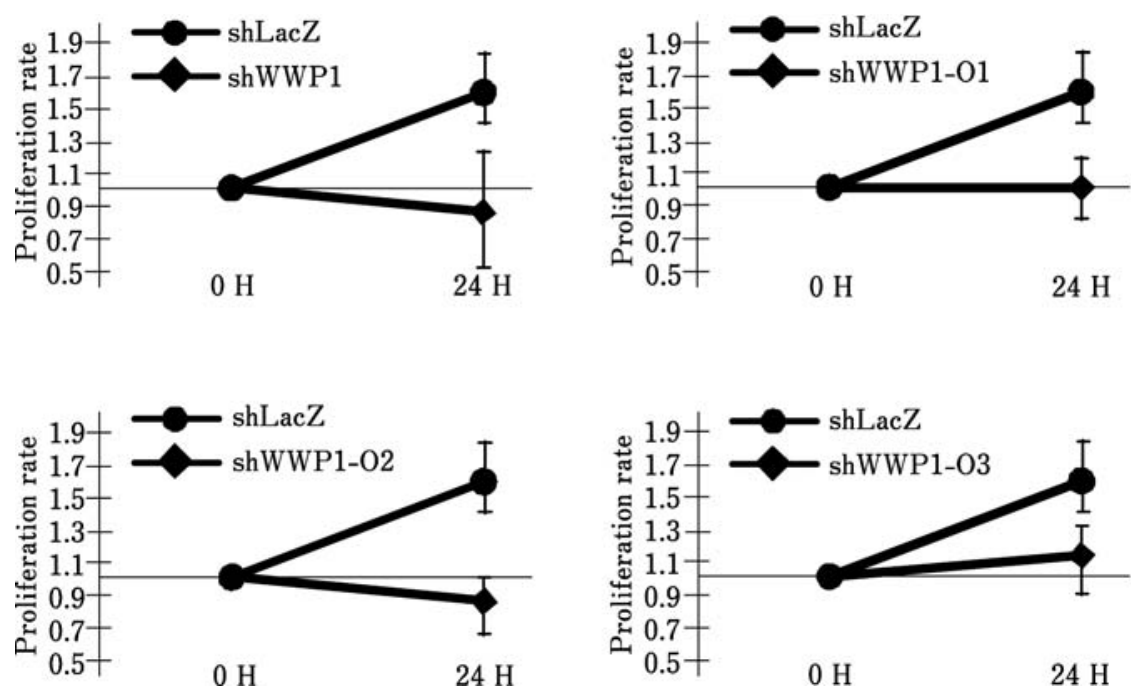

Fig. 3. The effects of four WWP1-shRNA sequences on $\mathbf{C}_{2} \mathbf{C}_{12}$ cells. In addition to the original one (shWWP1), three other WWP1-shRNA sequences (shWWP1-O1-3) were prepared and their effects on the proliferation rate of $\mathrm{C}_{2} \mathrm{C}_{12}$ cells were observed. All cells with shWWP1-O13 vectors showed significant downward tendencies as shWWP1-transfected cells twenty-four hours after transfection $(24 \mathrm{H})$ (shWWP1: $89 \pm$ 35\%, shWWP1-O1: 101 $22 \%$, shWWP1-O2: $83 \pm 16 \%$ and shWWP1O3: $110 \pm 22 \%)$. Y-axis indicates relative proliferation rate based on the cell numbers of immediately after transfection $(0 \mathrm{H})$. Three individual samples were prepared for each calculation. Definition of proliferation rate was depicted in Fig. 2. 


\section{References}

Augustine GJ. How does calcium trigger neurotransmitter release? Current Opinion in Neurobiology, 11: 320-326. 2001.

Bandman E. Continued expression of neonatal myosin heavy chain in adult dystrophic skeletal muscle. Science, 227: 780782. 1985.

Bandman E and Bennett T. Diversity of fast myosin heavy chain expression during development of gastrocnemius, bicep brachii, and posterior latissimus dorsi muscles in normal and dystrophic chickens. Developmental Biology, 130: 220-231. 1988.

Bernassola F, Karin M, Ciechanover A and Melino G. The HECT family of E3 ubiquitin ligases: multiple players in cancer development. Cancer Cell, 14: 10-21. 2008.

Chen $\mathrm{C}$ and Matesic LE. The Nedd4-like family of E3 ubiquitin ligases and cancer. Cancer Metastasis Reviews, 3-4: 587604. 2007.

Chen C, Zhou Z, Ross JS, Zhou W, Dong JT. The amplified WWP1 gene is a potential molecular target in breast cancer. International Journal of Cancer. Journal international du cancer, 121: 80-87. 2007.

Flasza M, Gorman P, Roylance R, Canfield AE and Baron M. Alternative Splicing Determines the Domain Structure of WWP1, a Nedd4 Family Protein. Biochemical and Biophysical Research Communications, 290: 431-437. 2002.

Flasza M, Nguyen Huu NS, Mazaleyrat S, Clémence S, Villemant C, Clarke R and Baron M. Regulation of the nuclear localization of the human Nedd4-related WWP1 protein by Notch. Molecular Membrane Biology, 23: 269-276. 2006.

Hershko A, Heller H, Elias S and Ciechanover A. Components of ubiquitin-protein ligase system. Resolution, affinity purification, and role in protein breakdown. Journal of Biological Chemistry, 258: 8206-8214. 1983.

Jackson PK, Eldridge AG, Freed E, Furstenthal L, Hsu JY, Kaiser BK and Reimann JDR. The lore of the RINGs: substrate recognition and catalysis by ubiquitin ligases. Trends in Cell Biology, 10: 429-439. 2000.

Kaprielian Z, Bandman E and Fambrough DM. Expression of $\mathrm{Ca}^{2+}$-ATPase isoforms in denervated, regenerating, and dystrophic chicken skeletal muscle. Developmental Biology, 144: 199-211. 1991.

Katso R, Okkenhaug K, Ahmadi K, White S, Timms J and Waterfield MD. Cellular function of phosphoinositide 3kinases: implications for development, homeostasis, and cancer. Annual Review of Cell and Developmental Biology, 17: 615-675. 2001.

Kitamura T, Kitamura YI, Funahashi Y, Shawber CJ, Castrillon DH, Kollipara R, DePinho RA, Kitajewski J and Accili D. A Foxo/Notch pathway controls myogenic differentiation and fiber type specification. The Journal of Clinical Investigation, 117: 2477-2485. 2007.

Komuro A, Imamura T, Saitoh M, Yoshida Y, Yamori T, Miyazono K and Miyazawa K. Negative regulation of transforming growth factor- $\beta$ (TGF- $\beta$ ) signaling by WW domaincontaining protein 1 (WWP1). Oncogene, 23: 6914-6923. 2004.

Liu YC. Ubiquitin ligases and the immune response. Annual Review of Immunology, 22: 81-127. 2004.

Matsumoto H, Inba Y, Sasazaki S, Fujiwara A, Ichihara N, Kikuchi $\mathrm{T}$ and Mannen $\mathrm{H}$. Mutated WWP1 induces an aberrant expression of myosin heavy chain gene in $\mathrm{C}_{2} \mathrm{C}_{12}$ skeletal muscle cells. Journal of Poultry Science, 47: 115-119. 2010.
Matsumoto H, Maruse H, Inaba Y, Yoshizawa K, Sasazaki S, Fujiwara A, Nishibori M, Nakamura A, Takeda S, Ichihara N, Kikuchi T, Mukai F and Mannen H. The ubiquitin ligase gene $(W W P 1)$ is responsible for the chicken muscular dystrophy. FEBS Letters, 582: 2212-2218. 2008.

Matsumoto H, Maruse H, Sasazaki S, Fujiwara A, Takeda S, Ichihara N, Kikuchi T, Mukai F and Mannen H. Expression pattern of $W W P 1$ in muscular dystrophic and normal chickens. Journal of Poultry Science, 46: 95-99. 2009.

Matsumoto H, Maruse H, Yoshizawa K, Sasazaki S, Fujiwara A, Kikuchi T, Ichihara N, Mukai F and Mannen H. Pinpointing the candidate region for muscular dystrophy in chickens with an abnormal muscle gene. Animal Science Journal, 78: 476-483. 2007.

Oswald F, Liptay S, Adler G and Schmid RM. NF- $\kappa$ B2 is a putative target gene of activated Notch-1 via RBP-J $\kappa$. Molecular and Cellular Biology, 18: 2077-2088. 1998.

Palomero $\mathrm{T}$ and Ferrando A. Oncogenic NOTCH1 control of MYC and PI3K: challenges and opportunities for antiNOTCH1 therapy in T-cell acute lymphoblastic leukemias and lymphomas. Clinical Cancer Research: an official journal of the American Association for Cancer Research, 14: 5314-5317. 2008.

Passmore LA and Barford D. Getting into position: the catalytic mechanisms of protein ubiquitylation. Biochemical Journal, 379: 513-525. 2004.

Pickart CM and Fushman D. Polyubiquitin chains: polymeric protein signals. Current Opinion in Chemical Biology, 8: 610-616. 2004.

Pirozzi G, McConnell SJ, Uveges AJ, Carter JM, Sparksi AB, Kayi BK and Fowlkes DM. Identification of Novel Human WW Domain-containing Proteins by Cloning of Ligand Targets. Journal of Biological Chemistry, 272: 14611-14616. 1997.

Plant PJ, Lafont F, Lecat S, Verkade P, Simons K and Rotin D. Apical membrane targeting of Nedd4 is mediated by an association of its C2 domain with annexin XIIIb. Journal of Cell Biology, 149: 1473-1484. 2000.

Plant PJ, Yeger H, Staub O, Howard P and Rotin D. The C2 domain of the ubiquitin protein ligase Nedd4 mediates $\mathrm{Ca}^{2+}$-dependent plasma membrane localization. Journal of Biological Chemistry, 272: 32329-32336. 1997.

Rao DD, Vorhies JS, Senzer N, Nemunaitis J. siRNA vs. shRNA: similarities and differences. Advanced Drug Delivery Reviews, 61: 746-59. 2009.

Ronchini C and Capobianco AJ. Induction of cyclin D1 transcription and CDK2 activity by Notch ${ }^{\text {ic }}$ : implication for cell cycle disruption in transformation by Notch ${ }^{\text {ic }}$. Molecular and Cellular Biology, 21: 5925-5934. 2001.

Semple CA, RIKEN GER Group and GSL Members. The comparative proteomics of ubiquitination in mouse. Genome Research, 13: 1389-1394. 2003.

Sudol M, Chen HI, Bougeret C, Einbond A and Bork P. Characterization of a novel protein-binding module: the WW domain. FEBS Letters, 369: 67-71. 1985.

Tidyman WE, Moore LA and Bandman E. Expression of fast myosin heavy chain transcripts in developing and dystrophic chicken skeletal muscle. Developmental Dynamics, 208: 491-504. 1997.

von Poser C, Zhang JZ, Mineo C, Ding W, Ying Y, Sudhof TC and Anderson RG. Synaptotagmin regulation of coated pit assembly. Journal of Biological Chemistry, 275: 3091630924. 2000. 